\title{
Denitrase activity of Debaryomyces hansenii reduces the oxidized compound 3-nitrotyrosine in mice liver with colitis
}

\author{
CLAUDIA MARISSA CALDERÓN-TORRES ${ }^{1}$, LIRIO SARABIA-CURZ ${ }^{1}$, YADIRA LEDESMA-SOTO ${ }^{1}$, \\ MIGUEL MURGUÍA-ROMERO ${ }^{2}$ and LUIS I. TERRAZAS ${ }^{1}$ \\ ${ }^{1}$ Biomedicine Unit; ${ }^{2}$ Morphology and Function Unit, Faculty of Higher Studies Iztacala, \\ National Autonomous University of Mexico, Tlalnepantla 54090, Mexico
}

Received July 24, 2018; Accepted February 20, 2019

DOI: $10.3892 /$ etm.2019.7395

\begin{abstract}
The oxidation of tyrosine to 3-nitrotyrosine is irreversible, and due to this characteristic, 3-nitrotyrosine is used as a marker for oxidative stress in a range of diverse chronic and degenerative diseases. It has been established that the yeast Debaryomyces hansenii (D. hansenii) can assimilate free 3-nitrotyrosine as unique source of nitrogen, and during saline stress, has a high denitrase activity to detoxify this compound in a reaction that involves the liberation of nitrogen dioxide from 3-nitrotyrosine. However, until now it has not been determined whether $D$. hansenii can detoxify protein-bound 3-nitrotyrosine such as nitrated proteins present in different chronic illnesses. TThe aim of the present study was to evaluate the denitrase activity of $D$. hansenii to reduce 3-nitrotyrosine from liver proteins of mice with colitis. Firstly, the levels of reactive oxygen species of liver tissue of colitic and control mice were measured by the reaction with the $2^{\prime} 7^{\prime}$-dichlorofluorescein diacetate. Denitrase activity of D. hansenii was evaluated by incubating cell extracts of the yeast with protein extracts from livers of mice with colitis. Following incubation, 3-nitrotyrosine was measured, and to corroborate that denitrase reaction had occurred, the production of nitrites was measured. In samples of liver tissue from mice with colitis, the maximum levels of reactive oxygen species were up to two times higher compared with the control livers. Following the incubation of colitic liver samples with cell extracts of D. hansenii, it was observed that 3-nitrotyrosine decreased to
\end{abstract}

Correspondence to: Dr Claudia Marissa Calderón-Torres, Biomedicine Unit, Faculty of Higher Studies Iztacala, National Autonomous University of Mexico, Ave de los Barrios 1, Los Reyes Iztacala, Tlalnepantla 54090, Mexico

E-mail: cmarissacalderon@gmail.com

Abbreviations: 3-NT, 3-nitrotyrosine; ROS, reactive oxygen species; RNS, reactive nitrogen species

Key words: Debaryomyces hansenii, oxidative stress, protein damage, denitrase activity, 3-nitrotyrosine (3-NT) reduction, chronic illness the basal concentration of control liver samples, and that the concentration of nitrites was increased. These results indicate that denitrase of $D$. hansenii extracts can effectively detoxify 3-nitrotyrosine bound to proteins and that the extracts could be used to decrease protein oxidation damage in chronic degenerative diseases.

\section{Introduction}

The oxidized compound 3-nitrotyrosine (3-NT) is employed as an oxidative stress marker. The tyrosine present in most proteins is a target for reactive nitrogen species (RNS), such as peroxynitrite $\left(\mathrm{ONOO}^{-}\right)$, which is produced by the reaction of superoxide $\left(\mathrm{O}_{2}^{-}\right)$with nitric oxide (NO). The ONOO- reacts extremely quickly with the aromatic amino acid tyrosine to form 3-NT $(1,2)$. The main problem of the occurrence of protein nitration is the alteration or inhibition of their function. The protein oxidation damage has been largely associated with the progression of some degenerative diseases such as non-alcoholic fat liver, colitis, lateral sclerosis, Alzheimer's disease and type 2 diabetes mellitus (3-5).

The non-alcoholic fatty liver disease (NAFLD) begins with hepatic steatosis, which is defined as the accumulation of triglycerides (TG) at the level of the cytoplasm, in histology is evidenced by the presence of droplets in cytoplasm of TG in more than $5 \%$ of the hepatocytes, steatosis may progress to a state of inflammation and cellular damage that may end in NAFLD and hepatic cirrhosis (6). In the pathogenesis of NAFLD it has been shown that the increase of free fatty acids leads to a deregulation of the ways of assimilation and release of free fatty acid in the liver, thus modifying the regulation of transcription of the genes of lipogenesis and their transport out of the liver $(7,8)$. The excess of TG overloads the carrier VLDL molecules, so VLDL-TG of greater diameter that exceed the sinusoidal pores of epithelium accumulate in the liver, and may generate stress in the endoplasmic reticulum (ER) and the activation of the pathway NF- $\mathrm{B}$, which increase the transcription of genes encoding for pro-inflammatory cytokines $(8,9)$.

In addition, the excess of fatty acids modifies the mitochondrial function, because when the fatty acids are processed by $\beta$-oxidation, this increases the substrates of the respiratory chain and the flow of electrons, which conduce to a higher production of oxygen and reactive nitrogen species (ROS and 
RNS) and may exceed the antioxidant response, and lead to oxidation of biomolecules.

In the case of ulcerative colitis (UC), the deficiencies of the intestine immune system and the epithelial barrier that prevents the entry of bacteria or antigens to the circulation, lead to inflammation, which causes a continuous deterioration of the epithelium and the exposure to microorganisms. In the lamina propia of the intestinal mucosa, the number of mature dendritic cells of the immune system also increases, including a large number of Toll-like (TLR) receptors, specifically TLR2 and TLR4, which are activated and lead to the transcription of genes that encode for pro-inflammatory cytokines. There is also an atypical response of $\mathrm{T}$ helper cells $(\mathrm{Th})$ in patients with ulcerative colitis, specifically Th2, which exerts a cytotoxic response against epithelial cells (10-12). In addition, the recruitment of leukocytes is affected, because UC increases the release of the chemo attractant molecule CXCL8, this activates the leukocytes recruiting from the systemic circulation to the intestinal mucosa, its entrance triggers an inflammatory response with a high production of ROS, which is a defense response to phagocytosis of bacteria, also the granular material or soluble irritating compounds increase ROS levels (13).

In intestinal and hepatic diseases, the common factor is an inflammatory condition, that begins with TLR4 receptors, and activates transcriptional factors such as $\mathrm{NF}-\kappa \mathrm{B}$, which in turn regulates the genetic expression of different pro-inflammatory cytokines, for example in fatty liver disease, there is an increase of TNF- $\alpha$, IL-8, IL- $1 \alpha$ and IL-1 $\beta$ (14). The cascade of TLR4 can induce alterations of the mitochondrial function and thus the increase of ROS production. Also, during the consumption of fat-rich diets, it has been shown there is an overexpression of TLR4 gene (15) and production of ROS (16).

In addition, a relationship of incidence of hepatic damage in patients with inflammatory diseases such as ulcerative colitis (17) has been found recently, which may be due to the passage of bacteria or endotoxins from the intestine to liver, that produces an inflammation of the liver and hepatobiliary damage, this condition is specifically termed cholangitis $(18,19)$. In patients with NAFLD the damage derived from UC can be a factor of susceptibility for progress to non-alcoholic steatohepatitis (NASH). As a result of the bacterial translocation, the endotoxin of the bacterial cover (LPS) is fixed to the type receptors of the cell surface and this promotes the production of the pro-inflammatory cytokines and production of ROS in the liver tissue. The establishment of incidence and correlation between different diseases is also explored in other diseases to prevent their worsening. For example, measurements of echocardiography of healthy and NAFLD patients were compared and a significant relationship was found, with an increase in the mass of the left ventricle of the myocardium in patients with NAFLD, the conclusion was that the echocardiography is a good indicator of decreased cardiac function and may be key to modify feeding habits in patients with NAFLD to improve cardiac function. In the case of UC, its evaluation and monitoring could be used to prevent liver damage.

The cells overcome the oxidative stress condition mainly by neutralization systems such as superoxide dismutase, catalase and oxide-reductase enzymes that react with ROS and in consequence diminish ROS and RNS (13). The cellular mechanisms to repair oxidative damage are scarce or null, such as the case of protein 3-NT elimination, which has been proposed as irreversible, and although an enzymatic like activity of denitrase for histone 3 to detoxify 3-NT has been demonstrated in humans (20), there are no data that clearly demonstrate the presence of denitrase enzyme in higher eukaryotic organisms. However, in microorganisms proteins have been found that degrade 3-NT, these are denitrases enzymes or flavoprotein monooxygenases that act directly on nitrated aromatic compounds to remove the nitro group, originally described in bacteria as oxygenase that in presence of an aromatic compound such as ortho or para nitrophenol, require a reduced substrate such as NADPH or NADH and oxygen to release nitrite (21-23). In the yeast Debaryomyces hansenii (D. hansenii), we found genes that encode for NADPH-dependent monooxygenase enzymes, and in total protein extracts of the yeast, we measured the specific activity of the denitrase with commercial free 3-nitrotyrosine and determined that $D$. hansenii can degrade to a concentration of $10 \mathrm{mM} 3-\mathrm{NT}$. It was also found that the yeast can assimilate 3-NT as the sole source of nitrogen (24).

The extremophile organisms are an excellent source to search for genes to detoxify oxidized molecules, such as the extreme halotolerant yeast $D$. hansenii, that during salt stress support a high ROS production $(25,26)$. In response, the yeast activates the transcription of genes to ameliorate oxidative stress. In a previous work, we reported that the increased expression of the RNA messenger of DhARO4 gene in $D$. hansenii is a strategy to survive to salt stress, because after the transcription of DhARO4 there is more enzyme to produce tyrosine, that is used as antioxidant compound to avoid the protein oxidation, because the free tyrosine can react with $\mathrm{ONOO}^{-}$that, in turn, reduces the $\mathrm{ONOO}^{-}$levels that can nitrate proteins. Taking into account this model, we supported our results, because after the overexpression of the DhARO4 gen, there is a high specific activity of the DhAro4p without an increase of tyrosine because we observed a maximum concentration of the 3-NT compound (27). In fact, after grown $D$. hansenii in a medium with high $\mathrm{NaCl}$ concentration, there is also oxidative stress and we proposed that the synthesis of tyrosine occurred immediately, this is oxidized to 3-NT as a mechanism to decrease the cell damage of high ROS or RNS production (26).

As we mentioned, recently we found that $D$. hansenii can assimilate 3 -NT as unique nitrogen source, and determined that the cell extract of this yeast has denitrase specific activity over residual free 3-NT (24). However, it is necessary determine whether the cell extracts of $D$. hansenii can revert the 3-NT oxidation when it is bound to proteins of higher eukaryotic organisms.

In this work, we evaluated the denitrase activity of $D$. hansenii in liver proteins from mice with and without colitis measuring the ROS production and the 3-NT oxidative marker, and evaluating the nitrite concentration to corroborate the removal of $\mathrm{NO}_{2}$ from $3 \mathrm{NT}$.

\section{Materials and methods}

Mice. Female BALB/c mice were purchased from Envigo México (Envigo RMS S.A., Coyoacán, Mexico). Six to eight weeks old mice were used in this study. All mice were housed 
under specific pathogen-free conditions according to Faculty Animal Care and Use Committe and government guidelines (Official Mexican regulation NOM-062-ZOO-1999).

DSS-induced colitis. The model of colitis in mice was implemented according to Ledesma-Soto (28). Briefly, BALB/c strain mice were assigned to the control or colitis group. The control group received standard food with free access to water, whereas the colitis group received in their drinking water $4 \%$ dextran sodium sulphate (DSS) (MW: 40000; Alfa Aesar) for 7 to 10 days to cause colitis. The mice were weighted daily to evaluate the body weight percent. At the end of the treatament, the mice were euthanized in a $\mathrm{CO}_{2}$ chamber and liver samples with or without colitis were placed in $2 \mathrm{ml}$ polypropylene conical tubes, immediately frozen with liquid nitrogen and stored at $-70^{\circ} \mathrm{C}$ for later use.

Histology. Ethanol-fixed colon tissues were embedded in a paraffin block. Distal parts of colons obtained from colitis mice at day 9 were cut into $5 \mu \mathrm{m}$ and used for hematoxylin and eosin (H\&E) staining. The histological severity of colitis was examined under a microscope (Axio Vert A1, Carl Zeiss), tissue samples stained with $\mathrm{H} \& \mathrm{E}$ and were based on the extent of edema, ulceration, crypt loss and infiltration of immune cells as previously described (29).

Mice liver crude extracts. The crude extracts were done according to the modified assay of Song (30). Then, $200 \mathrm{mg}$ of each sample was taken and to remove the excess of blood, samples were washed with $1 \mathrm{X}$ phosphate buffer (PBS). The tissue was transferred to a $2 \mathrm{ml}$ propylene conical tube and added $500 \mu 1$ of $1 \mathrm{X}$ PBS. Cellular lysis was done with PTFE micro pestle and $5 \mu \mathrm{l}$ of $100 \mathrm{mM}$ phenylmethylsulfonyl fluoride (PMSF) (SIGMA-ALDRICH). The cellular macerate was centrifuged at $13,000 \mathrm{xg}$ for $10 \mathrm{~min}$ at $4^{\circ} \mathrm{C}$. The aqueous phase was transferred to a new tube and kept on ice. The protein concentration was determined using the UV light spectrophotometry method at $280 \mathrm{~nm}$ and a standard curve of bovine serum albumin (BSA; Sigma-Aldrich; Merck KGaA, Darmstadt, Germany).

ROS production. ROS levels were determined in the liver extracts of M. musculus by the reaction of ROS with the 2'7'dichlorofluorescein diacetate (DCFA-DA) (Sigma-Aldrich; Merck KGaA), according to the modified method of Hempel (31). With this method, the increase of fluorescence is used as index of the production of ROS in the sample. From each cell extract, $50 \mu 1$ were placed in triplicate in a 96-well plate and $195 \mu \mathrm{l}$ of $1 \mathrm{X}$ PBS and $5 \mu \mathrm{l}$ of $500 \mu \mathrm{M}$ DCFA-DA were added. The plate was placed in a fluorometer with 96-well plate reader (BioTek Instruments, Inc., Winooski, VT, USA); the fluorescence was recorded at an excitation wavelength of $485 \mathrm{~nm}$ and emission of $520 \mathrm{~nm}$ for $60 \mathrm{~min}$. The fluorescence value was reported as the relative fluorescence unit per $\mathrm{mg}$ of total protein in the crude extract.

$D$. hansenii growth conditions. The yeast $D$. hansenii strain Y7426 (CBS 767) was obtained from the Department of Agriculture of Peoria (Peoria, IL, USA). The strain was maintained in YPD medium (yeast extract $1 \%$, peptone $1 \%$ and glucose 2\%) (Sigma-Aldrich; Merck KGaA) and Agar 1.5\% (Sigma-Aldrich; Merck KGaA). In order to grow D. hansenii in salt stress, first a pre-culture of the yeast was made in YPD medium for $24 \mathrm{~h}$ at $28^{\circ} \mathrm{C}$ with constant stirring $(250 \mathrm{rpm})$. Then aliquots were taken from the preculture to inoculate three Erlenmeyer flasks with YPD medium and/or 1 and $2 \mathrm{M} \mathrm{NaCl}$ (JT Baker, Phillipsburg, NJ, USA). Cultures were started with an optical density (OD) of 0.01 to 0.2 . Cells were collected by centrifugation when the cultures reached OD value of 0.8 to 1 at $600 \mathrm{~nm}$. D. hansenii crude extracts were obtained (26). The protein concentration was determined using the UV light spectrophotometric method at $280 \mathrm{~nm}$ and a standard curve of BSA.

Incubation assay of crude extracts of mice liver and yeast. From each liver crude extract (with and without colitis) and yeast (YPD, with 1 and $2 \mathrm{M} \mathrm{NaCl}$ ), $100 \mu \mathrm{g} \mathrm{ml}$ of proteins were added to each eppendorf tube. The capacity of denitrase activity was evaluated according to the modified assay of Zeyer and Kocher (21). To each extract mixture $4 \mathrm{mM}$ NADPH (Sigma-Aldrich; Merck KGaA) and $4 \mathrm{mM} \mathrm{MgSO}_{4}$ (Sigma-Aldrich; Merck KGaA) were added and the volume was adjusted to $100 \mu 1$ with $1 \mathrm{X}$ PBS, each sample was kept at room temperature for $30 \mathrm{~min}$, then frozen at $-70^{\circ} \mathrm{C}$.

3-NT concentration in crude extracts. 3-NT-modified proteins in the mixture of extracts were quantified by a 3-NT primary antibody (enzyme-linked immunosorbent assay) assay (Ab116691; Abcam, Cambridge UK) following the instructions of the supplier. Quantification was done against a standard curve of nitrated BSA (Ab116691; Abcam). From each sample an aliquot was taken which was added to each well of the plate and incubated for two $h$ at room temperature. Subsequently the secondary antibody was added which recognizes the 3-NT antibody and changes color when the HRP substrate is added. The plate was read on a UV-VIS spectrophotometer (BioTek Instruments, Inc.) at a wavelength of $600 \mathrm{~nm}$.

Nitrite production. The concentration of nitrites from 3-NT degradation was determined in all extracts with the Griess reaction of the commercial nitrite and nitrate system (no. 780001; Cayman Chemical Company, Ann Arbor, MI, USA). The added Griess reagents sulfanilamide and $\mathrm{n}$-(1-naphthyl) ethylendiamine react with the nitrite to form a violet diazonium salt choromophore, whose concentration is determined by measuring absorbance at $545 \mathrm{~nm}$. The samples were read on a 96-well plate reader spectrometer (BioTek Instruments, Inc.) at a wavelength of $545 \mathrm{~nm}$.

Statistical analysis. In order to establish whether the differences in the values of the parameters of experimental and control mice were statistically significant, a Student's t-test was applied when the sample number of mice were five to six (data of change of weight and ROS concentration). While in the determinations with a number of mice of three, as the case of 3-NT and $\mathrm{NO}_{2}$ concentrations, the data were analyzed with a Kruskal-Wallis to establish if there were differences among experimental and control groups; next, a Mood's median test was applied as a pos hoc test for comparisons between pairs of groups using Bonferroni correction. $\mathrm{P}<0.05$ 
was considered to indicate a statistically significant difference.

\section{Results}

Induction of colitis in a mouse model by Dextran sodium sulphate (DSS). Taking into account that in the model of murine colitis severe intestine damage has been reported, we wanted to evaluate whether there was also liver damage and we established first the model of colitis according to Ledesma-Soto (28). We then evaluated whether the intestine damage can affect the liver. We corroborated that $4 \%$ DSS induces colitis when it is administered orally for 9 days (Fig. 1A). During the course of the experiment, the treated mice exhibited profound body weight loss (Fig. 1B) and bloody diarrhea, whereas the control group exhibited no symptoms. Histological analysis indicated that DSS generates signs of the histological damage such as abnormal crypts, crypts loss, and inflammatory cell infiltration (Fig. 1C).

Colitis produces an increase of ROS and protein damage in liver. To evaluate liver damage, we measured the reactive oxygen species (ROS) in liver samples of mice with and without colitis. The crude extracts of mice liver without colitis had a ROS level of 79 relative units of fluorescence (RUF) total protein $\bullet \mathrm{mg}^{-1}$. In contrast the crude extracts of mice liver with colitis presented higher ROS level 130.6 RUF total protein $\bullet \mathrm{mg}^{-1}$, (Fig. 2), these results indicate that effectively, ROS levels increase in the liver samples from mice with colitis.

Considering the high ROS production observed in the samples of liver from mice with colitis, we evaluated whether the samples displayed oxidation of proteins such as the formation of 3-NT. Next, we measured the concentration of 3-NT. We observed that samples of liver from mice without colitis showed an average concentration of $3-\mathrm{NT}$ of $36.8 \mathrm{ng} \bullet \mathrm{ml}^{-1}(\mathrm{n}=3)$ while the samples of liver from mice with colitis displayed significant higher 3 -NT concentrations $78.1 \mathrm{ng} \bullet \mathrm{ml}^{-1}(\mathrm{n}=3)$ compared to normal mice, these data suggest a higher protein oxidation damage in the liver of mice with colitis.

Denitrases of Debabryomyces hansenii decrease the levels of oxidation of proteins of mice liver with colitis. In order to evaluate the denitrase capacity of $D$. hansenii to reduce protein-bound 3-NT, we performed incubation assays of crude extracts of liver samples (with and without colitis) with crude extracts of D. hansenii. Also, we considered that higher denitrase activity was reported in cell extracts of the yeast grown with 1 and $2 \mathrm{M} \mathrm{NaCl}$ (24), thus we included these cell growth conditions to obtain the cell extracts. We found that in the incubation assay, in which the samples of control and colitis liver were incubated with cells extract of $D$. hansenii grown in YPD medium, the higher value of 3-NT corresponded to the samples with colitis, because, first, the samples of colitis, as we described above, had a higher 3NT concentration, and second, the YPD growth condition is not stressful for the yeast and in consequence, there is only a basal denitrase activity (24). However, in the incubation assay in which the cell extract of D. hansenii grown in $1 \mathrm{M} \mathrm{NaCl}$, the 3-NT concentration of samples with colitis decreased and dropped their values below that obtained in the control samples (Fig. 3). Moreover, in the incubation assay of the samples with colitis and the cell extract
A
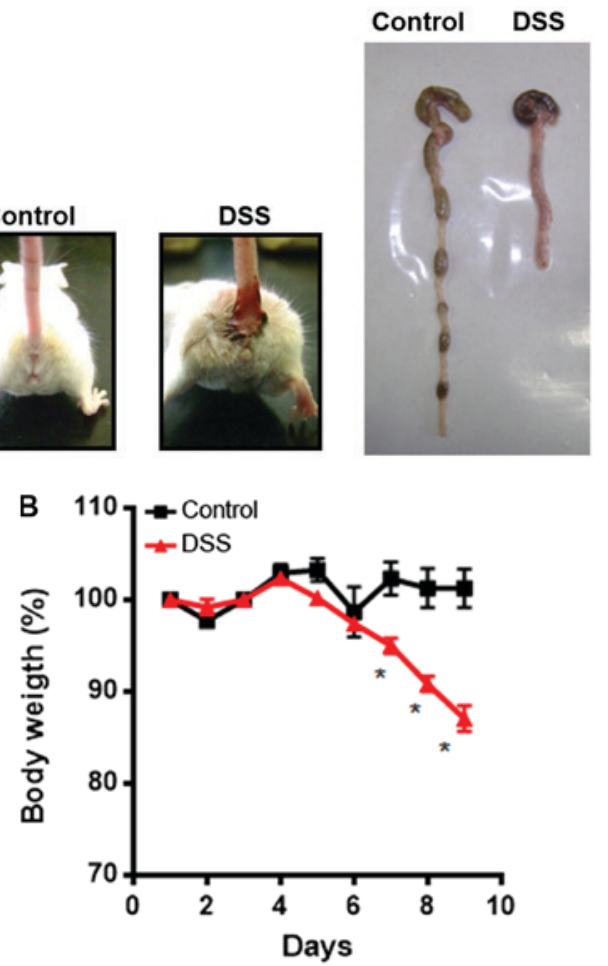

C
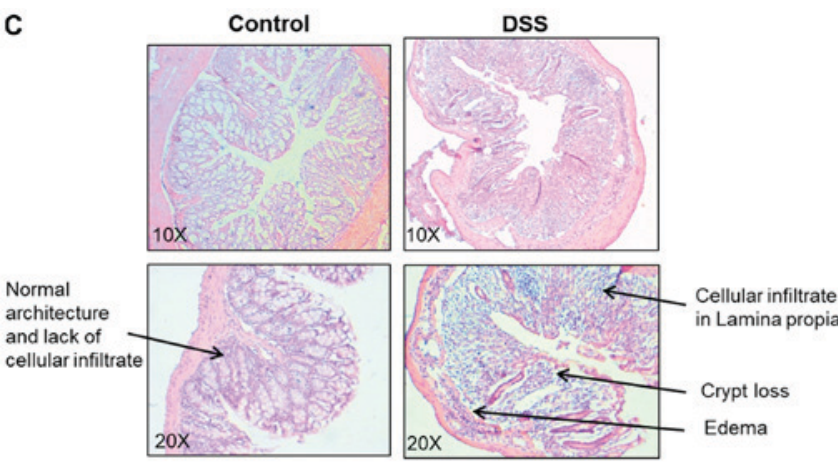

Figure 1. DSS induces murine colitis. Mice drinking 4\% DSS for 9 days, the control group drinking only water without DSS. (A) The photographs show mice without colitis and mice with DSS-induced colitis, and the mice colon after the dissection of the organs; (B) Body weight change, representative results of 5 mice are shown. Each value represents means \pm SD ( $\mathrm{n}=5$ mice/group), ${ }^{*} \mathrm{P}<0.01$; (C) Colon histology, colons were removed, fixed and stained with $\mathrm{H} \& \mathrm{E}$, arrows indicate normal colon histology in mice without colitis and damage in mice with DSS-induced colitis. DSS, dextran sodium sulphate; H\&E, hematoxylin and eosin.

of $D$. hansenii grown with $2 \mathrm{M} \mathrm{NaCl}$, the 3-NT levels were significantly lower compared with control samples. The lack of reduction of 3-NT concentration in the control and colitis samples when the cell extracts of the yeast were recovered from YPD medium, and the increase of degradation of 3-NT with cell extracts of $D$. hansenii grown in 1 and $2 \mathrm{M} \mathrm{NaCl}$, suggest de novo synthesis of denitrase enzyme to overcome the oxidative damage generated during salt stress.

Decreased levels of 3-nitrotyrosine in liver samples with colitis are notorious, comparing the levels in the samples incubated with the yeast cell extract grown in YPD medium against those of the extract with $2 \mathrm{M} \mathrm{NaCl}$ (Fig. 3), it is observed that there is a $50 \%$ decrease in $3-\mathrm{NT}$ levels, this fact underscores the decrease of oxidized proteins of colitis with the denitrase of the cellular extract of $D$. hansenii. 


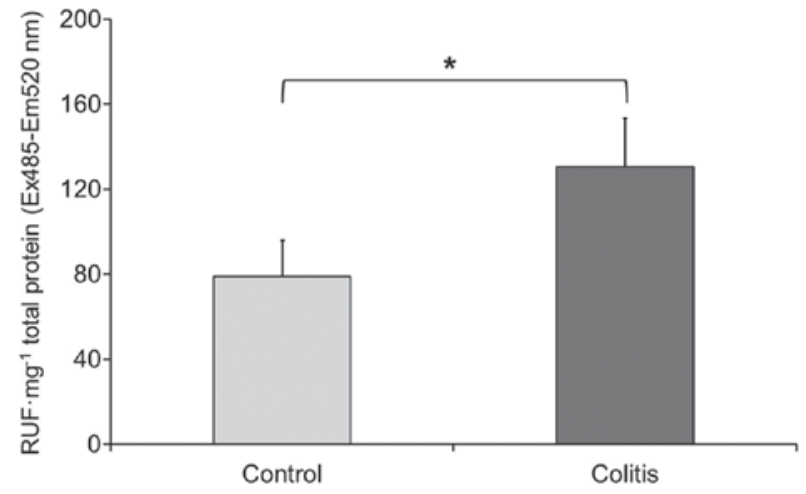

Figure 2. ROS in protein samples of mice liver with colitis. ROS production of liver protein samples of control mice without colitis $(n=4)$ and mice with DSS-induced colitis $(n=6)$, is expressed as relative units of fluorescence after 50 min of reaction with DCFA-DA. Error bars are SEM, ${ }^{*} \mathrm{P}<0.05$. ROS, reactive oxygen species; DSS, dextran sodium sulphate; DCFA-DA, dichlorofluorescein diacetate; SEM, standard error of the mean.

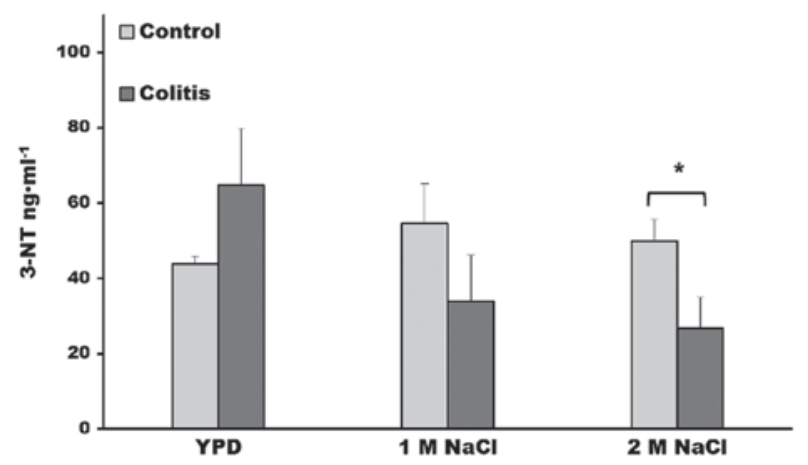

Figure 3. 3-NT concentration in protein samples of liver with and withou colitis after incubation with $D$. hansenii extracts. The concentration of 3 -NT in liver protein extracts of mice liver with or without colitis $(n=3)$ was measured after incubating for $30 \mathrm{~min}$ the liver protein samples with the total protein extracts of $D$. hansenii. For each sample of hepatic protein three incubations were made: with the extracts of the yeast grown in YPD medium without sodium, and with 1 and $2 \mathrm{M} \mathrm{NaCl}$. Error bars are SEM; significant results with pos hoc Mood's median test comparison are indicated with an asterisk (") when $\mathrm{P}<0.05$. 3-NT, 3-nitrotyrosine; SEM, standard error of the mean.

Denitrase activity increases nitrite production. It is known that after a denitrase reaction occurrs there is an increase in the nitrite levels (22). Thus, next we quantified the nitrites concentration after the incubation assay of crude extracts of livers with the crude extract of the yeast. We found in the liver samples without yeast extract that the concentration of nitrites were 0.41 and $0.37 \mu \mathrm{M}$, respectively (Fig. 4). By contrast, after the incubation with the yeast extract the nitrites reached the highest concentration, and significant differences of nitrites were observed in colitis samples incubated with the extract of yeast grown in $1 \mathrm{M} \mathrm{NaCl}$ (Fig. 4B). However, we observed almost the same value of nitrites concentration in the incubation assay of control and colitis samples with the crude extract of the yeast grown in $2 \mathrm{M} \mathrm{NaCl}$ (Fig. 4).

\section{Discussion}

The oxidative-mediated damage of proteins is a key event in many degenerative and inflammatory diseases $(32,33)$. In the
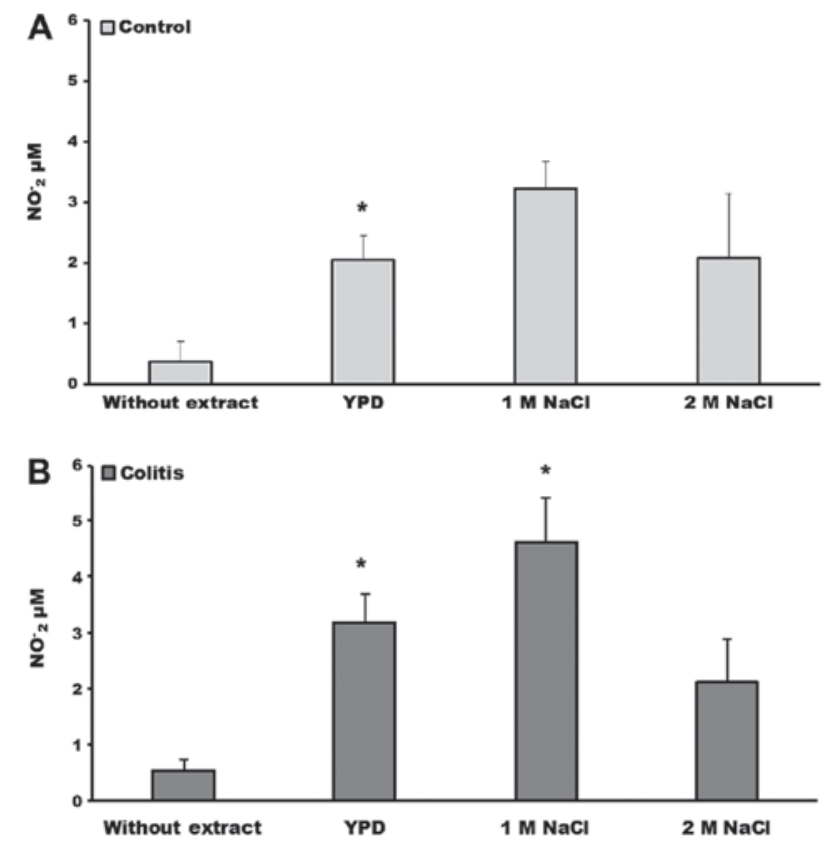

Figure 4. Nitrite production after 3-NT detoxification in proteins from liver of mice with colitis. (A) control and (B) colitis. The concentration of nitrites in total protein extracts of liver of mice with and without colitis $(n=4$ and $\mathrm{n}=3$ per group), was measured after incubating for $30 \mathrm{~min}$ the liver protein samples with the total protein extracts of $D$. hansenii. For each sample of hepatic protein three incubations were made: with the extracts of the yeast grown in YPD medium without sodium, and with 1 and $2 \mathrm{M} \mathrm{NaCl}$. Error bars are SEM; "significant differences compared with samples without extract of yeast with a pos hoc Mood's median test when $\mathrm{P}<0.05$. 3-NT, 3-nitrotyrosine; SEM, standard error of the mean

present study, we provided evidence that colitis can affect other organs such as liver, given that we observed an increase of ROS production in the crude extracts of livers from mice with colitis. In this respect, research is scarce, due to the complexity of evaluating that a disease such as colitis or obesity in animal models lead to oxidative stress condition in the liver $(16,34)$.

The research about inflammatory disease such as colitis is fundamental to establish strategies to decrease the damage of liver and preserve its functions. In particular, it has been demonstrated in colitis that the oxidative stress condition leads to oxidation of biomolecules, which can be detrimental, if the oxidation modifies or inhibits protein functions, for example, when the irreversible oxidation of tyrosine occurs to form 3-NT (35).

To date, a specific biological system has not been reported in higher eukaryotes that reverts the oxidation of the 3-NT bound to proteins. In a previous work, we demonstrated that D. hansenii can assimilate free 3-NT as a unique source of nitrogen and that in vitro the crude extracts of this yeast have denitrase activity (24), but it is necessary to provide evidence on whether or not such denitrase activity may function with 3-NT bound to proteins. To our knowledge this is the first report demonstrating that cell extracts from $D$. hansenii cultured in salt stress conditions have a potent denitrase activity that is able to degrade 3-NT in protein samples of liver from mice with acute colitis. Also, we demonstrated that the crude extracts of $D$. hansenii grown in 1 and $2 \mathrm{M} \mathrm{NaCl}$ has the highest denitrase activity, and this fact is in agreement with the postulate of the transcriptional response of $D$. hansenii to 
overcome the effects of the oxidative stress condition generated during salt stress $(24,27)$.

Our findings are supported by an expected increase in the nitrite concentration, because when the reaction of denitrase occurs, the 3-NT disappears and the nitrite concentration increases, as has been shown by Nishino (22). In particular, we found an elevated increase of nitrites in the liver samples from mice with colitis, this result can be taken as an additional demonstration that the 3-NT concentration was higher in the liver of mice with colitis because there was an elevated ROS production. And, as we suspected, in the assays where we used the cell extracts of $D$. hansenii grown in salt stress, nitrite production increased due to the high denitrase activity observed in 1 and $2 \mathrm{M} \mathrm{NaCl}$ conditions. However, in the $2 \mathrm{M} \mathrm{NaCl}$ crude extract of the yeast there was no higher increase of nitrites concentration, probably because the sodium residual in the cell extracts reacts with nitrites to form nitrates, as occurred in the reaction of nitrite oxidation in presence of sodium $(36,37)$.

The present work is preliminary and in further studies of in vivo application of the yeast extract in a mouse model of colitis, we consider carrying out a liver function test, by measuring hepatic enzymes in blood, such as $\gamma$-glutamyl transferase (GGT), aspartate transaminase (AST), alanine aminotransferase (ALT) or alkaline phosphatase, because these enzymes are released from the liver in response to damage or disease; a measurement and identification of nitrated proteins of liver and blood by HPLC and mass spectrometry, will be useful to stablish the kind and number of nitrated proteins before and after application of the yeast extract, for example it has been determined that both the glutamine synthase and apolipoprotein A1 are nitrated in inflammatory and hepatic diseases (2). Given that in this work we determine only whether there were changes in the production of ROS in the liver of mice with or without colitis, we consider using ROS determination in specific cells employing flow cytometry. All of these measurements are required to state the results of the present study.

In conclusion, here we presented evidence that the yeast D. hansenii possess a high denitrase activity to detoxify oxidized 3-NT bound to proteins. This finding will benefit experimental and therapeutic medicine, considering that oxidation of proteins in degenerative and chronic diseases is a problem in medicine today. Also the demand for repair mechanisms justify the need for more effective therapy approaches. Thus the research that put in practice strategies to revert the oxidation damage derived from the results of this study will be able to make a breakthrough in medicine, because the study will help uncover a critical area in the reduction of the oxidized compound 3-NT that inhibits or modifies the function of proteins and because until now there is not a report giving evidence of a gene or enzyme that reduces this compound in humans. Thus a new application to reduce oxidation in inflammatory diseases and thereby ameliorate the symptoms and perhaps stop the progress to more severe illness may found.

\section{Acknowledgements}

We are grateful to Dr Antonio Peña Díaz (Institute of Cellular Physiology, National Autonomous University of Mexico) for his kind support of this study.

\section{Funding}

This study was partially financed by grant no. N226716 from National Autonomous University of Mexico, DGAPA-PAPIIT.

\section{Availability of data and materials}

The datasets used and/or analyzed during the current study are available from the corresponding author on reasonable request.

\section{Authors' contributions}

CMC-T was responsible for study design. YL-S and LS-C performed the experiments. Data interpretation and statistical analysis was performed by CMC-T, LS-C and MM-R. LIT-V was involved in drafting the manuscript and revising it critically for important intellectual content. All authors read and approved the final manuscript.

\section{Ethics approval and consent to participate}

The animal research protocol for this work were reviewed and approved by the ethics committee (CE/FESI/042017/1168), Faculty of Higher Studies Iztacala, National Autonomous University of Mexico, Mexico.

\section{Patient consent for publication}

Not applicable.

\section{Competing interests}

The authors declare that they have no competing interests.

\section{References}

1. Ischiropoulos H: Biological tyrosine nitration: A pathophysiological function of nitric oxide and reactive oxygen species. Arch Biochem Biophys 356: 1-11, 1998.

2. Ahsan H: 3-Nitrotyrosine: A biomarker of nitrogen free radical species modified proteins in systemic autoimmunogenic conditions. Hum Immunol 74: 1392-1399, 2013.

3. Brownlee M: Biochemistry and molecular cell biology of diabetic complications. Nature 414: 813-820, 2011.

4. Ceriello A and Testa R: Antioxidant anti-inflammatory treatment in type 2 diabetes. Diabetes Care 32 (Suppl 2): S232-S236, 2009.

5. Butterfield DA, Reed T and Sultana R: Roles of 3-nitrotyrosineand 4-hydroxynonenal-modified brain proteins in the progression and pathogenesis of Alzheimer's disease. Free Radical Res 45: 59-72, 2011.

6. Academia Nacional de Medicina de México: Enfermedad por hígado graso no alcohólico. Boletín De Información Clínica Y Terapéutica 24: 7-8, 2015.

7. Di Rosa M and Malaguarnera L: Genetic variants in candidate genes influencing NAFLD progression. J Mol Med (Berl) 90: 105-118, 2012.

8. Botteri G, Montori M, Gumà A, Pizarro J, Cedó L, Escolà-Gil JC, Li D, Barroso E, Palomer X, Kohan AB and Vázquez-Carrera M: VLDL and apolipoprotein CIII induce ER stress and inflammation and attenuate insulin signaling via Toll-like receptor 2 in mouse skeletal muscle cells. Diabetologia 60: 2262-2273, 2017.

9. Ipsen DH, Lykkesfeldt J and Tveden-Nyborg P: Molecular mechanisms of hepatic lipid accumulation in non-alcoholic fatty liver disease. Cell Mol Life Sci 75: 3313-3327, 2018.

10. Danese S and Fiocchi C: Ulcerative colitis. N Engl J Med 365: 1713-1725, 2011. 
11. Kmieć Z, Cyman M and Ślebioda TJ: Cells of the innate and adaptive immunity and their interactions in inflammatory bowel disease. Adv Med Sci 62: 1-16, 2017.

12. Ungaro R, Mehandru S, Allen PB, Peyrin-Biroulet L and Colombel JF: Ulcerative colitis. Lancet 389: 1756-1770, 2017.

13. Wang J, Sun H, Meng P, Wang M, Tian M, Xiong Y, Zhang X and Huang P: Dose and time effect of CdTe quantum dots on antioxidant capacities of the liver and kidneys in mice. Int J Nanomedicine 12: 6425-6435, 2017.

14. Stojsavljević S, Gomerčić Palčić M, Virović Jukić L, Smirčić Duvnjak L and Duvnjak M: Adipokines and proinflammatory cytokines, the key mediators in the pathogenesis of nonalcoholic fatty liver disease. World J Gastroenterol 20: 18070-18091, 2014.

15. Manček-Keber M, Frank-Bertoncelj M, Hafner-Bratkovič I, Smole A, Zorko M, Pirher N, Hayer S, Kralj-Iglič V, Rozman B, Ilc N, et al: Toll-like receptor 4 senses oxidative stress mediated by the oxidation of phospholipids in extracellular vesicles. Sci Signal 8: ra60, 2015.

16. Ortiz-Reyes AE and Calderón-Torres CM: Incremento de la expresión de TLR4 y efecto antioxidante del ácido acetilsalicílico en conejos con dieta alta en grasas. Revista De Salud Pública Y Nutrición 16: 1-10, 2017.

17. Solís-Herruzo JA and Solís-Muñoz P: Manifestaciones hepatobiliares en la enfermedad inflamatoria Intestinal. Rev Esp De Enferm Dig 99: 525-542, 2007.

18. Erkan G: Inflammatory bowel disease and primary sclerosing cholangitis. Ulcerative colitis epidemiology, pathogenesis and complications. Dr Mortimer O'Connor (eds.). ISBN: 978-953-307-880-889, 2011.

19. Dohan A, Faraoun SA, Barral M, Guerrache Y, Boudiaf M, Dray X, Hoeffel C, Allez M, Farges O, Beaugerie L, et al: Extra-intestinal malignancies in inflammatory bowel diseases: An update with emphasis on MDCT and MR imaging features. Diagn Interv Imaging 96: 871-883, 2015.

20. Smallwood HS, Lourette NM, Boschek CB, Bigelow DJ, Smith RD, Pasa-Tolić L and Squier TC: Identification of a denitrase activity against calmodulin in activated macrophages using high-field liquid chromatography-FTICR mass spectrometry. Biochemistry 46: 10498-10505, 2007.

21. Zeyer $\mathrm{J}$ and Kocher HP: Purification and characterization of a bacterial nitrophenol oxygenase which converts ortho-nitrophenol to catechol and nitrite. J Bacteriol 170: 1789-1794, 1988.

22. Nishino SF and Spain JC: Biodegradation of 3-nitrotyrosine by Burkholderia sp. strain JS165 and Variovorax paradoxus JS171. Appl Environ Microbiol 72: 1040-1044, 2006.

23. Arora PK, Srivastava A and Singh VP: Application of monooxygenases in dehalogenation, desulphurization, denitrification and hydroxylation of aromatic compounds. J Bioremed Biodegrad 1: $112,2010$.

24. Castro DE, Murguía-Romero M, Thomé PE, Peña A and Calderón-Torres M: Putative 3-nitrotyrosine detoxifying genes identified in the yeast Debaryomyces hansenii: In silico search of regulatory sequences responsive to salt and nitrogen stress. Electron J Biotechn 29: 1-6, 2017.

25. Chao HF, Yen YF and Ku MS: Characterization of a salt-induced DhAHP, a gene coding for alkyl hydroperoxide reductase, from the extremely halophilic yeast Debaryomyces hansenii. BMC Microbiol 9: 182, 2009.
26. Calderón-Torres M, Castro DE, Montero P and Peña A: DhARO4 induction and tyrosine nitration in response to reactive radicals generated by salt stress in Debaryomyces hansenii. Yeast 28: 733-746, 2011.

27. Calderón-Torres M, Peña A and Thomé PE: DhARO4, an amino acid biosynthetic gene, is stimulated by high salinity in Debaryomyces hansenii. Yeast 23: 725-734, 2006.

28. Ledesma-Soto Y, Callejas BE, Terrazas CA, Reyes JL, Espinoza-Jiménez A, González MI, León-Cabrera S, Morales R, Olguín JE, Saavedra R, et al: Extraintestinal helminth infection limits pathology and proinflammatory cytokine expression during DSS-induced ulcerative colitis: A role for alternatively activated macrophages and prostaglandins. Biomed Res Int 2015: $563425,2015$.

29. Chang YC, Ching YH, Chiu CC, Liu JY, Hung SW, Huang WC, Huang YT and Chuang HL: TLR2 and interleukin-10 are involved in Bacteroides fragilis-mediated prevention of DSS-induced colitis in gnotobiotic mice. PLoS One 12: e0180025, 2017.

30. Song J, Ke SF, Zhou CC, Zhang SL, Guan YF, Xu TY, Sheng CQ, Wang P and Miao CY: Nicotinamide phosphoribosyltransferase is required for the calorie restriction-mediated improvements in oxidative stress, mitochondrial biogenesis, and metabolic adaptation. J Gerontol A Biol Sci Med Sci 69: 44-57, 2014.

31. Hempel SL, Buettner GR, O'Malley YQ, Wessels DA and Flaherty DM: Dihydrofluorescein diacetate is superior for detecting intracellular oxidants: comparison with 2',7'-dichlorodihydrofluorescein diacetate, 5(and 6)-carboxy-2',7'-dichlorodihydrofluorescein diacetate, and dihydrorhodamine 123. Free Radic Biol Med 27: 146-159, 1999.

32. Gadjeva VS, Goycheva P, Nikolova G and Zheleva A: Influence of glycemic control on some real-time biomarkers of free radical formation in type 2 diabetic patients: An EPR study. Adv Clin Exp Med 26: 1237-1243, 2017.

33. Zuwała-Jagiełło J, Pazgan-Simon M, Simon K and Warwas M: Elevated advanced oxidation protein products levels in patients with liver cirrhosis. Acta Biochim Pol 56: 679-685, 2009.

34. Bronsart L, Nguyen L, Habtezion A and Contag C: Reactive oxygen species imaging in a mouse model of inflammatory bowel disease. Mol Imaging Biol 18: 473-478, 2016.

35. Souza JM, Choi I, Chen Q, Weisse M, Daikhin E, Yudkoff M, Obin M, Ara J, Horwitz J and Ischiropoulos H: Proteolytic degradation of tyrosine nitrated proteins. Arch Biochem Biophys 380: $360-366,2000$

36. Winkler T, Goschinick $\mathrm{J}$ and Ache HJ: Reactions of nitrogen oxides with $\mathrm{NaCl}$ as model of sea salt aerosol. J Aerosol Sci 22 (Suppl 1): S605-S608, 1991.

37. Sun CC and Chou TC: Kinetic of anodic oxidation of nitrite ion using in situ electrogenerated $\mathrm{HCIO}$ in a $\mathrm{NaCl}$ aqueous solution. Ind Eng Chem Res 38: 4545-4551, 1999. 